\title{
Rt. Hon. Lord Rutherford of Nelson, O.M., F.R.S.
}

ERnest Rutherford was born at Nelson, New Zealand, on August 30, 187I. He was the son of a farmer, James Rutherford, of Taranaki. His paternal grandfather had emigrated from the south of Scotland. He was educated at Nelson College and at Canterbury College, Christchurch. He took the M.A. degree of New Zealand University with first-class honours in Mathematics and Physics in I893. He was awarded an I 85 I Exhibition Scholarship in I894.

Rutherford came to Cambridge in October 1895 to work in the Cavendish Laboratory under J. J. Thomson. The discovery of argon had been published at the beginning of that year, that of X-rays in the autumn; the electron and radio-activity were to be discovered during the next three years. No time could have been more favourable for a young physicist to begin research in the Cavendish Laboratory.

Rutherford had already before leaving New Zealand begun experiments on wireless telegraphy, and he continued them in Cambridge. He very soon, however, joined Thomson in his investigations on the conduction of electricity through gases exposed to X-rays. The first systematic measurements on the mobilities of the ions produced in gases by these rays were made by Rutherford in 1897 , and he had made important contributions to this subject before his appointment as Professor of Physics in McGill University, Montreal, in 1898.

Rutherford remained in Montreal till 1907. In that year he was made Langworthy Professor of Physics in the University of Manchester; in 1919 he became Cavendish Professor in Cambridge.

His discovery, shortly after going to Montreal, of the radio-active "emanation" from thorium and of the characteristic law of decay of its activity was the starting-point of the researches which led Rutherford and Soddy to put forward in 1902-3 their transformation theory of the radio-active elements. All the subsequent work on radio-activity served to confirm this view, which at first seemed so startling, that the radioelements are undergoing spontaneous transmutations.

It is largely to Rutherford that our knowledge of the nature of the alpha particle is due. He may be said to have discovered the alpha ray while a research student at Cambridge, when he proved by absorption experiments that the rays from uranium were of two types which he named $a$ - and $\beta$-rays. He later showed that the alpha ray is a positively 
charged particle, measured its charge and mass, and proved that it is a doubly charged helium atom, i.e. a helium nucleus. This work on the nature of the a-particle was begun by Rutherford in Montreal; it was completed in Manchester by decisive experiments made in collaboration with Geiger and with Royds.

The alpha particle, with the scintillation method of detecting it, became in Rutherford's hands a most effective weapon for investigating the structure of the atom. Experiments on the "scattering" of alpha particles, made by himself and his pupils in Manchester, led him to the view, which later experiments have only served to confirm, that the atom is a very open electronic structure containing at its centre a minute positively charged nucleus in which most of the mass of the atom is concentrated. For many years Rutherford and his collaborators in Manchester and Cambridge continued to use the alpha particle as a projectile for gaining information about the interior of the atom.

It was by using a-particles as projectiles to bombard the nucleus itself that what is perhaps Rutherford's most famous achievement was accomplished-the first artificial transmutation of an element, nitrogen. This was in 1919; a few years later in collaboration with Chadwick he succeeded in disintegrating twelve light elements - in each case with ejection of a proton.

The rapid advances in nuclear physics and chemistry made in recent years, largely due to the use of more effective projectiles than the alpha particles-neutrons, fast protons, and deuterons-owe much directly and indirectly to Rutherford. A very important share of the work has been done in the Cavendish Laboratory.

The great part which Rutherford's work has played in the development of modern Physics and Chemistry has been universally recognised, and it would be impossible to enumerate here all the honours which came to him. He bore them easily.

He was elected a Fellow of the Royal Society in 1903 and was awarded the Rumford medal in 1905, the Copley medal in 1922; he received the Nobel prize for Chemistry in 1908, the Franklin medal in 1924. A knighthood was conferred on him in 1914, the O.M. in 1925; he became Baron of Nelson and Cambridge in $193 \mathrm{I}$.

Rutherford was a man of immense vigour; in spite of his great output of scientific research he had superabundant energy to expend in other ways. The training and supervision of the large number of research students working in his laboratory was always one of his main interests. In this work he had latterly able assistance from younger colleagues, most of whom had received their training in research under him. He 
took his full share in University business. He was Professor of Natural Philosophy at the Royal Institution, and also found time to give lectures to many scientific and popular audiences which were always original and stimulating. He was President of the British Association in 1923, of the Royal Society from 1925 to 1930 . For the last seven years he was Chairman of the Advisory Council of the Department of Scientific and Industrial Research. On any committee on which he served he was an efficient and forceful member. He did a great service to Science by his three books relating to radio-active substances and their radiations, the latest of them being written in collaboration with Ellis and Chadwick.

There was little evidence of any falling off in Rutherford's powers with advancing years. He died after only a few days' illness on October 19, 1937; his ashes were buried in Westminster Abbey near the graves of Newton, Kelvin, and Darwin.

Rutherford married in 1900 Mary G. Newton, only, daughter of Arthur and Mary de Renzy Newton of Christchurch, New Zealand. They had one daughter, who became the wife of Professor R. H. Fowler, F.R.S. She died in 1930, leaving two sons and two daughters.

Rutherford was elected an Honorary Fellow of this Society in $192 \mathrm{I}$.

See also Obituary Notices of Fellows of the Royal Society, vol. ii, No. 6, 1938 .

C. T. R. W. 